\title{
Repetitive tests of visual function improved visual acuity in young subjects
}

\author{
Juliane Otto, ${ }^{1}$ Georg Michelson ${ }^{2}$
}

- Additional material is published online only. To view please visit the journal online (http://dx.doi.org/10.1136/ bjophthalmol-2013-304262).

${ }^{1}$ Department of Ophthalmology, FriedrichAlexander-Universität ErlangenNürnberg, Erlangen, Germany

${ }^{2}$ Department of

Ophthalmology

Interdisciplinary Center of Ophthalmic Preventive Medicine and Imaging, Friedrich-Alexander-Universität, Erlangen, Germany

\section{Correspondence to}

Prof. Dr. med. Georg Michelson, Department of Ophthalmology, FriedrichAlexander-Universität ErlangenNürnberg, Erlangen, Germany; georg.michelson@uk-erlangen. de

Received 2 September 2013 Revised 31 October 2013 Accepted 30 November 2013 Published Online First 3 January 2014
CrossMark

To cite: Otto J,

Michelson G. Br J

Ophthalmol 2014;98:

383-386.

\section{ABSTRACT}

Aims To test visual function after repetitive tests of visual acuity (VA) and contrast sensitivity (CS).

Methods Ten young female subjects performed repetitive tests of visual functions over ten sessions within 5 weeks. Per week they performed two $30 \mathrm{~min}$ sessions of repetitive tests of central VA, CS and vernier acuity (VT) using Michael Bach's Freiburg Vision Test FrACT 3.5.5. FrACT presents an optotype in different spatial frequencies or an optotype with decreasing contrast. Using SPSS Statistics we analysed the correlation between the number of repetitive test sessions and the change in visual function of the total group and of the individuals.

Results/conclusion After ten sessions, we found a significant improvement in VA, CS and VT. When compared with the initial session, VA increased by $32 \%$, mean CS improved by $40 \%$ and mean VT enhanced by $47 \%$. We also found a significant correlation between the number of test sessions and VA ( $r=-0.374$, $p<0.01), C S(r=-0.258, p<0.05)$ and VT $(r=-0.379$, $p<0.01$ ). Individual changes in vision were variable. In eight subjects, VA and CS improved significantly. VT improved in nine subjects. Our data suggest that repetitive tests of visual function may improve VA significantly.

\section{INTRODUCTION}

Visual perceptual learning (VPL) has been used to improve vision without changing the optics. Studies with patients suffering from amblyopia or presbyopia have been run as well as studies of normal subjects. ${ }^{1-4}$ Most of them revealed proof for VPL. The studies showed that the visual system adapts quite well to changes in visual input from our environment by using the cortical plasticity of the adult human brain. ${ }^{5-8}$ Polat $^{9}$ found improvement in visual acuity (VA), contrast sensitivity (CS) and reaction time after perceptual training. Thus, we suppose that also repetitive tests of VA and CS may improve the visual performance.

\section{MATERIALS AND METHODS}

Ten young women (age 19-29) of the Olympic Training Centre for professional fencing in Tauberbischofsheim took part in this study. Nine of them were professional fencers and one was a psychological advisor. Before perceptual training, all participants underwent automated tests (CANON R-50 auto refractometer, peripheral vision of motion with Frequency Doubling Technology), measurement of VA, CS and vernier threshold (VT accounting for vernier acuity) by Michael Bach's computer-assisted Freiburg Vision Test 3.5.5. The distance between the participants and the test screen was $4 \mathrm{~m}$. The participants got auditory feedback after every trial.

For testing VA, a Landolt $\mathrm{C}$ with an open annulus to eight possible directions was used. The participants had to make a guess if they did not know the correct answer to reduce the influence of the so-called response criterion.

For determining the CS threshold, FrACT displayed both a Landolt $\mathrm{C}$ and the background in different shades of grey, representing medium spatial frequencies. The vernier acuity task in FrACT was based on two-line-segment alignment.

The participants started with best-corrected vision. As baseline, the average VA was -0.195 $\pm 0.08 \log$ MAR and the average CS was $1.181 \%$ $\pm 0.04 \%$. The maximum VA was $-0.277 \log$ MAR, and the maximum CS was $0.48 \%$. The repetitive visual tasks included two weekly training sessions. Each session consisted of three periods of $10 \mathrm{~min}$ of repetitive tasks with a short break in between. Thus, VA, CS and VT were tested repetitively 50 times in each period. That means within one 30 min training session 150 values for each measured variable were acquired. These measured values were transformed into mean values of VA, CS and VT for each session.

One participant dropped out after session 5. Thus, we analysed 10 test sessions per subject (session 1-5: $\mathrm{N}=10$ subject; session 6-10: $\mathrm{N}=9$ subjects), setting the initial session as baseline.

The values of VA, CS and VT were correlated with the number of test sessions. The progress of all participants as a group was analysed as well as the individual progress in VA, CS and VT in percentage of baseline. The statistical analysis was performed with SPSS Statistics V.19.1 and V.20.0. The Pearson two-sided test that was used for regression analysis is reliable, indicated by $F>1$. Significance was calculated by non-parametric Wilcoxon signed-rank tests for related samples.

\section{RESULTS}

\section{Mean values of VA, CS and VT for the total} group

Mean values of VA, CS and VT of all participants as a group improved significantly with increasing number of test sessions (table 1). After performing 10 test sessions, the mean improvement in VA was $32 \%$, CS increased by $40 \%$ and vernier acuity improved by $47 \%$.

Figure 1A,B shows the mean values of the whole group during 10 test sessions. VA showed a continuous improvement over time, especially in sessions 7-10. For CS and VT, we found a stronger variability from session to session. Contrast 

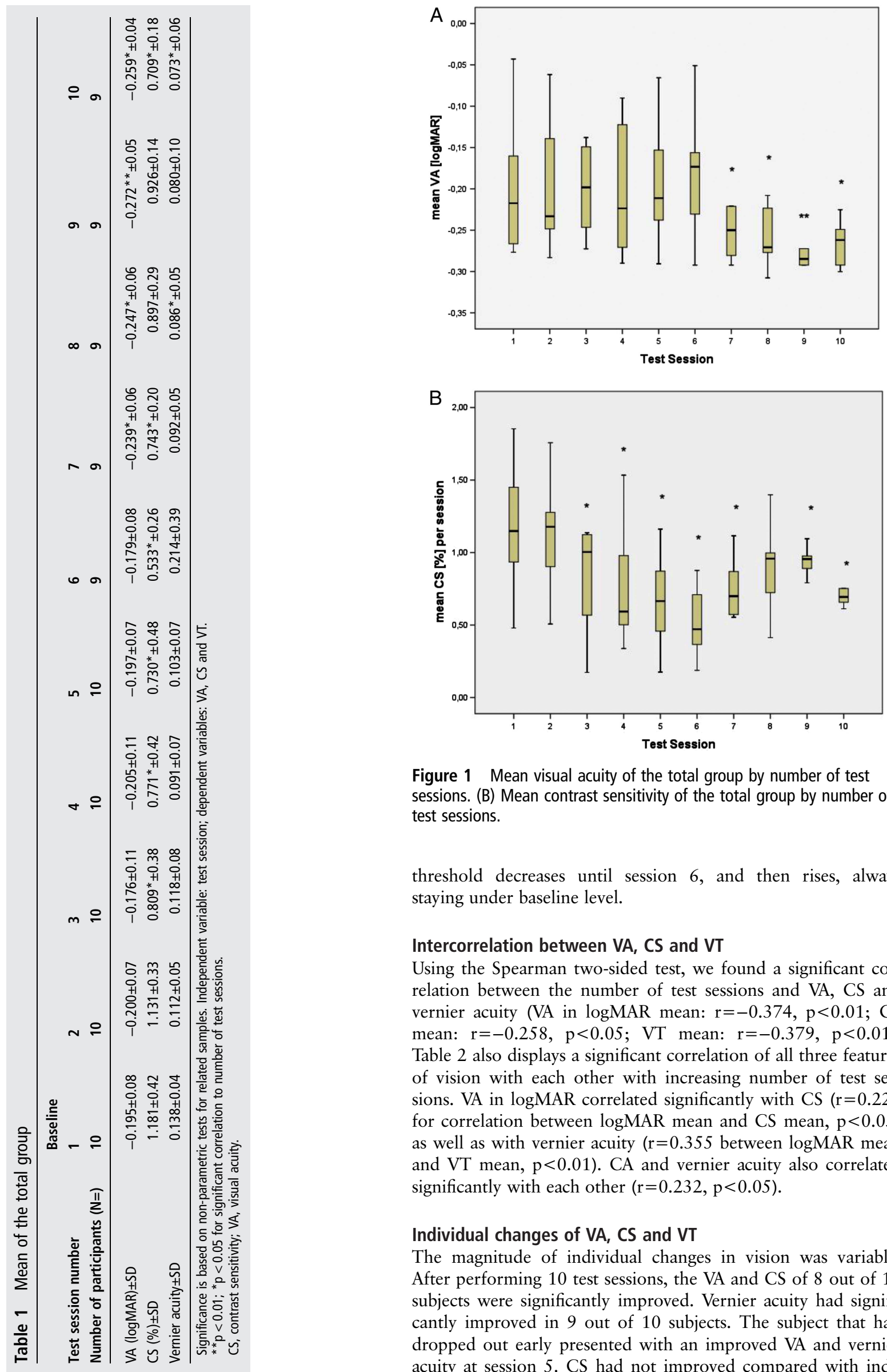

Figure 1 Mean visual acuity of the total group by number of test sessions. (B) Mean contrast sensitivity of the total group by number of test sessions.

threshold decreases until session 6, and then rises, always staying under baseline level.

\section{Intercorrelation between VA, CS and VT}

Using the Spearman two-sided test, we found a significant correlation between the number of test sessions and VA, CS and vernier acuity (VA in logMAR mean: $r=-0.374, p<0.01$; CS mean: $\mathrm{r}=-0.258, \mathrm{p}<0.05$; VT mean: $\mathrm{r}=-0.379, \mathrm{p}<0.01$ ). Table 2 also displays a significant correlation of all three features of vision with each other with increasing number of test sessions. VA in $\log$ MAR correlated significantly with CS $(r=0.226$ for correlation between $\log$ MAR mean and CS mean, $\mathrm{p}<0.05$ ) as well as with vernier acuity $(r=0.355$ between $\log$ MAR mean and VT mean, $\mathrm{p}<0.01)$. CA and vernier acuity also correlated significantly with each other $(r=0.232, p<0.05)$.

\section{Individual changes of VA, CS and VT}

The magnitude of individual changes in vision was variable. After performing 10 test sessions, the VA and CS of 8 out of 10 subjects were significantly improved. Vernier acuity had significantly improved in 9 out of 10 subjects. The subject that had dropped out early presented with an improved VA and vernier acuity at session 5. CS had not improved compared with individual baseline. 
Table 2 Correlation analysis for the total group for 10 sessions

\begin{tabular}{lccc}
\hline & Mean VA & Mean CS & Mean vernier \\
\hline Test session & $-0.374^{* *}$ & $-0.258^{*}$ & $-0.379^{* *}$ \\
Mean VA & 1 & $0.226^{*}$ & $0.355^{* *}$ \\
Mean CS & $0.226^{* *}$ & 1 & $0.232^{*}$ \\
Mean vernier & $0.355^{* *}$ & $0.232^{*}$ & 1 \\
\hline VA, CS and VT correlated significantly with the number of test sessions and they also \\
intercorrelated with each other. \\
${ }^{*}$ Correlation is significant on the 0.05 level (two-sided). \\
${ }^{* *}$ Correlation is significant on the 0.01 level (two-sided). \\
CS, contrast sensitivity; VA, visual acuity.
\end{tabular}

The online supplementary figure S2A,B shows the time course of the individual progress in VA, CS and VT, each coloured line indicating one individual participant and the dashed line representing the mean values.

\section{Normalised change in vision}

As the baseline in VA, CS and VT was different in the subjects, normalisation of baseline values was performed. The mean value of the first session of each subject was set as $100 \%$. With increasing number of test sessions, the individual vision improved as percentage. The difference in $\%$ to the baseline of VA (table 3 ) increased by $17 \%(p<0.01)$, and for vernier acuity the percentage of progress decreased by $35 \%(p<0.01)$. The longer the participants performed repetitive tests, the greater the mean change per session in VA was. The percentage of progress for threshold contrast (table 4) was 31\% to baseline but showed no significance $(\mathrm{p}>0.05)$.

A regression analysis showed that the number of performed repetitive tests correlated with vision. The number of performed tests accounted for $12 \%$ of the variance in VA, $5 \%$ in CS and $1 \%$ in VT.

\section{DISCUSSION}

The neural mechanisms of VPL have been well investigated within the last 20 years. Studies ${ }^{10} 11{ }^{12}$ have shown an improvement in visual functions after perceptual learning of different visual tasks.

In this study, we showed that repetitive tests in VA over 5 weeks improved visual performance in young subjects. It has been demonstrated before that solving visual tasks of any kind, such as playing video games, can lead to an improvement of visual performance.

FrACT was used to test VA, CS and vernier acuity. Our results after repetitive tests using FrACT showed that VA, CS and vernier acuity improved, although the participants had started from different individual baselines. After performing 10 test sessions within 5 weeks, the mean improvement in VA was $32 \%$,
CS increased by $40 \%$, and vernier acuity improved by $47 \%$. The results indicated that VA had the most constant improvement. The progress in VTwas smaller, and the percentage difference to baseline decreased during the time course. CS improved regarding absolute mean values, but the progress was not consistent enough to show a significant percentage development in one direction.

The vast majority of subjects showed better results in visual functions after repetitive tests than in the beginning.

It is very probable that this phenomenon is due (1) to the plasticity of the visual cortex and (2) the customisation to the test method. ${ }^{6} 713$

It is suggested that VPL could be achieved by improvement in sensitivity and/or a gain of neurons. Both mechanisms enable a more precise and even faster processing of visual tasks. ${ }^{5-8}$ The processing speed can either be induced by a higher sensitivity or directly by the repetitive training of visual tasks. ${ }^{4}$ It was proposed that improvement in VA, CS and VT is related with each other and that VPL is not only task-specific to a certain kind of visual input but can also be transferred to other visual functions. ${ }^{9}{ }^{14}$ It is assumed that VPL of one specific task influences the performance in other visual tasks and is therefore not strictly task relevant.

Some of the participants took part in more than 10 test sessions and were able to maintain their visual functions up to 7 months. We chose four sample subjects that were tested for 35-60 sessions. Of the sample analysis of every fifth test session of the long-term participants, we found in all four participants an ongoing improvement in VA. Three of four participants sustained a mean improvement of $30 \%$ (see online supplementary figure S1). In CS (see online supplementary figure S2), the mean improvement over the long-term sessions was 45\%, while one participant deteriorated by $26 \%$ mean. Considering this trend in our study and various examples for the sustainability of visual perceptual training effects in literature, ${ }^{36} 615$ we suppose that our participants can take advantage of VPL longer than the repetitive testing lasts.

VPL is useful in many fields of ophthalmology. Polat et al proved that the effects of presbyopia can be delayed and/or overcome by repetitive VPL. As perceptual and motor learning use similar cortical pathways, ${ }^{16}$ VPL might have an impact on all types of sports that require excellent vision. Visual training is already part of the training schedule of professional baseball and cricket players. ${ }^{17} 18$ In conclusion, we found that repetitive tests of VA improved vision in young athletes. Eight out of ten improved their visual functions.

A limiting factor of this study's value is the small group of only 10 participants. VA, CS and vernier acuity were performed using FrACT only. The measurements of vision were not validated with another visual test, such as the Snellen chart.

Table 3 Individual VA (logMAR) at baseline compared with VA at tenth test session

\begin{tabular}{|c|c|c|c|c|c|c|c|c|c|c|c|}
\hline Participant & 1 & 2 & 3 & 4 & 5 & 6 & 7 & 8 & 9 & 10 & Mean \pm SD \\
\hline VA at baseline & -0.043 & -0.266 & -0.248 & -0.209 & -0.160 & -0.188 & -0.226 & -0.277 & -0.276 & -0.061 & $10.195 \pm 0.08$ \\
\hline VA after 10 training sessions & -0.183 & -0.266 & -0.292 & -0.249 & -0.238 & -0.260 & -0.300 & -0.262 & -0.292 & -0.225 & $-0.259 \pm 0.04$ \\
\hline$\Delta \mathrm{VA}_{10-1}$ (absolute; approx. \%) & $\begin{array}{c}0.14 \\
-326 \%\end{array}$ & $\begin{array}{l}0 \\
0\end{array}$ & $\begin{array}{l}-0.044 \\
+17 \%\end{array}$ & $\begin{array}{l}-0.04 \\
+19 \%\end{array}$ & $\begin{array}{l}-0.078 \\
+49 \%\end{array}$ & $\begin{array}{l}-0.072 \\
+38 \%\end{array}$ & $\begin{array}{l}-0.074 \\
+33 \%\end{array}$ & $\begin{array}{l}0.015 \\
-5 \%\end{array}$ & $\begin{array}{l}-0.016 \\
+6 \%\end{array}$ & $\begin{array}{l}-0.164 \\
+269 \%\end{array}$ & $\begin{array}{l}10.033 \pm 0.08 \\
17 \% \\
\pm 143\end{array}$ \\
\hline
\end{tabular}




\section{Clinical science}

Table 4 Individual contrast sensitivity (CS) (\%) at baseline compared with CS at tenth test session

\begin{tabular}{|c|c|c|c|c|c|c|c|c|c|c|c|}
\hline Participant & 1 & 2 & 3 & 4 & 5 & 6 & 7 & 8 & 9 & 10 & Mean \pm SD \\
\hline CS at baseline & 1.450 & 0.480 & 0.935 & 1.059 & 1.637 & 1.391 & 0.719 & 1.055 & 1.237 & 1.853 & $1.181 \pm 0.42$ \\
\hline $\mathrm{CS}$ after 10 training sessions & 0.921 & 0.752 & 0.612 & 0.693 & 1.797 & 0.981 & 0.362 & 0.675 & 0.657 & 0.729 & $0.709 \pm 0.18$ \\
\hline$\Delta \mathrm{CS}_{10-1}$ (absolute; approx. \%) & $\begin{array}{l}-0.529 \\
-36 \%\end{array}$ & $\begin{array}{l}0.272 \\
57 \%\end{array}$ & $\begin{array}{l}-0.323 \\
-35 \%\end{array}$ & $\begin{array}{l}-0.366 \\
-35 \%\end{array}$ & $\begin{array}{l}0.16 \\
10 \%\end{array}$ & $\begin{array}{l}-0.41 \\
-29 \%\end{array}$ & $\begin{array}{l}-0.357 \\
-50 \%\end{array}$ & $\begin{array}{l}-0.38 \\
-36 \%\end{array}$ & $\begin{array}{l}-0.58 \\
-47 \%\end{array}$ & $\begin{array}{l}-1.124 \\
-61 \%\end{array}$ & $\begin{array}{l}-0.364 \pm 0.39 \\
-31 \% \\
\pm 36\end{array}$ \\
\hline
\end{tabular}

$\Delta \mathrm{CS}_{10-1}=\mathrm{CS}_{10-} \mathrm{CS}_{1}$. A negative absolute difference and a negative percentage difference indicate an improvement. The smaller the threshold contrast (\%), the better the contrast sensitivity.

Acknowledgements We thank Mrs Silvia Amend for supporting the measurement and the data entry.

Collaborators Silvia Amend.

Contributors GMmade substantial contributions to conception and design, acquisition and interpretation of data, and revised the article critically for important intellectual content. JO made substantial contributions to analysis and interpretation of data, and drafted the article. Silvia Amend supported the study.

Competing interests None.

Patient consent Obtained.

Ethics approval World Medical Association Declaration of Helsinki. Ethical Principles for Medical Research Involving Human Subjects.

Provenance and peer review Not commissioned; externally peer reviewed.

\section{REFERENCES}

1 Andersen GJ, Ni R, Bower JD, et al. Perceptual learning, aging, and improved visual performance in early stages of visual processing. J Vis 2010;10:4.

2 Bower JD, Andersen GJ. Aging, perceptual learning, and changes in efficiency of motion processing. Vis Res 2012;61:144-56.

3 Polat U, Ma-Naim T, Belkin M, et al. Improving vision in adult amblyopia by perceptual learning. Proceedings of the National Academy of Sciences of the United States of America 2004;101:6692-7.

4 Polat U, Schor C, Tong J-L, et al. Training the Brain to Overcome the Effect of Aging on the Human Eye. Sci Rep 2012;2:278. DOI:10.1038/srep00278

5 Gilbert CD, Sigman M, Crist RE. The neural basis of perceptual learning. Neuron 2001;31:681-97.
6 Polat U. Perceptual learning induces neuroplasticity, enabling improvement of visual functions. Expert RevOphthalmol 2009;4:573-76.

7 Gilbert CD, Li W, Piech V. Perceptual learning and adult cortical plasticity. J Physiol 2009;587(Pt 12):2743-51.

8 Hamamé CM, Cosmelli D, Henriquez R, et al Neural mechanisms of human perceptual learning: electrophysiological evidence for a two-stage process. PloS ONE 2011;6:e19221.

9 Polat U. Making perceptual learning practical to improve visual functions. Vis Res 2009;49:2566-73.

10 Lu ZL, Hua T, Huang CB, et al. Visual perceptual learning. Neurobiol Learn Mem 2011;95:145-51.

11 Sasaki Y, Nanez JE, Watanabe T. Advances in visual perceptual learning and plasticity. Nat Rev Neurosci 2010;11:53-60.

12 Caplovitz GP, Kastner S. Carrot sticks or joysticks: video games improve vision. Nat Neurosci 2009;12:527-8

13 Sterkin A, Yehezkel O, Polat U. Learning to be fast: gain accuracy with speed. Vision Res 2012;61:115-24.

14 Seitz AR, Watanabe T. The phenomenon of task-irrelevant perceptual learning. Vis Res 2009;49:2604-10

15 Levi DM, Li RW. Improving the performance of the amblyopic visual system. Philos Trans R Soc Lond B Biol Sci 2009:364:399-407.

16 Paz R, Wise SP, Vaadia E. Viewing and doing: similar cortical mechanisms for perceptual and motor learning. Trends Neurosci 2004;27:496-503.

17 Regan D. Vision and cricket. Ophthalmic Physiol Opt 2012; 32:257-70.

18 Clark JF, Ellis JK, Bench J, et al High-performance vision training improves batting statistics for University of Cincinnati Baseball Players. PlOS ONE 2012;7: e29109 


\section{Repetitive tests of visual function improved visual acuity in young subjects}

Juliane Otto and Georg Michelson

$\mathrm{Br} J$ Ophthalmol 2014 98: 383-386 originally published online January 3, 2014

doi: 10.1136/bjophthalmol-2013-304262

Updated information and services can be found at:

http://bjo.bmj.com/content/98/3/383

\section{These include:}

Supplementary Supplementary material can be found at:

Material http://bjo.bmj.com/content/suppl/2014/01/06/bjophthalmol-2013-3042 62.DC1.html

References This article cites 16 articles, 2 of which you can access for free at: http://bjo.bmj.com/content/98/3/383\#BIBL

Email alerting service

Receive free email alerts when new articles cite this article. Sign up in the box at the top right corner of the online article.

\section{Notes}

To request permissions go to:

http://group.bmj.com/group/rights-licensing/permissions

To order reprints go to:

http://journals.bmj.com/cgi/reprintform

To subscribe to BMJ go to:

http://group.bmj.com/subscribe/ 